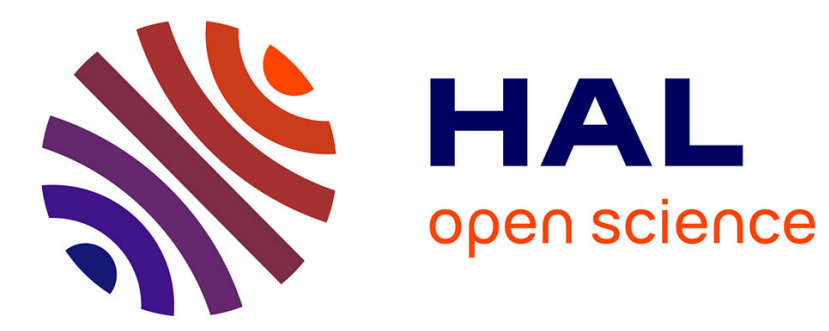

\title{
Normal and Tangential Contact Between Anisotropic Materials
}

\author{
C. Bagault, Marie-Christine Baietto, D. Nelias
}

\section{To cite this version:}

C. Bagault, Marie-Christine Baietto, D. Nelias. Normal and Tangential Contact Between Anisotropic Materials. ASME/STLE 2011 International Joint Tribology Conference, Oct 2011, Los Angeles, United States. pp.265-267, 10.1115/IJTC2011-61026 . hal-01951692

\section{HAL Id: hal-01951692 \\ https://hal.science/hal-01951692}

Submitted on 18 Mar 2019

HAL is a multi-disciplinary open access archive for the deposit and dissemination of scientific research documents, whether they are published or not. The documents may come from teaching and research institutions in France or abroad, or from public or private research centers.
L'archive ouverte pluridisciplinaire HAL, est destinée au dépôt et à la diffusion de documents scientifiques de niveau recherche, publiés ou non, émanant des établissements d'enseignement et de recherche français ou étrangers, des laboratoires publics ou privés. 


\title{
NORMAL AND TANGENTIAL CONTACT BETWEEN ANISOTROPIC MATERIALS
}

\author{
C. Bagault \\ M.-C. Baietto \\ D. Nélias \\ Université de Lyon, CNRS, INSA-Lyon, LaMCoS UMR5259, F-69621, France
}

\begin{abstract}
A contact model using semi analytic methods, relying on elementary analytic solutions, has been developed. It is based on numeric techniques adapted to contact mechanics, with strong potential for inelastic, inhomogeneous or anisotropic problems. Recent developments aim to quantify displacements and stresses of an anisotropic material which is in contact with another anisotropic material. The influence of symmetry axes on the contact problem solution will be more specifically analyzed.
\end{abstract}

\section{INTRODUCTION}

Engineering problems are becoming more complicated when trying to reduce the gap between the model and the real application. It means that less restrictive assumptions should be made, or in other words more physics should be implemented in the model. Among the challenges to succeed in it, the material properties should be considered accurately. Supposing the material is isotropic is not enough. For most composite and mono-crystal materials their compositions or the elaboration and manufacturing processes imply that it exits one or two main directions or even a general anisotropy. The influence of the anisotropy orientations have to be taken into account to better predict the stress state in order to optimize the service life of industrial components.

Several methods can be used for contact simulation of anisotropic materials. Semi analytical methods have proven their efficiency in contact mechanics and are developed here to account for anisotropy of materials. The main advantage is here the computing time compared to the Finite Element (FE) method that is however widely used for many contact problems. The contact model with its specificities when at least one of the bodies in contact behaves anisotropically will be first presented. Then, the influence of some parameters on the contact pressure distribution and strain and stress fields will be studied. The effect of the anisotropy orientation on the contact solution will be then investigated.

\section{NOMENCLATURE}

$\mathrm{E}_{1}$ Young modulus in direction 1

$\mathrm{E}_{3} \quad$ Young modulus in direction 3

\author{
$\mathrm{R}^{\mathrm{T}} \quad$ Transpose of the matrix $\mathrm{R}$ \\ $\mathrm{u}_{\mathrm{k}} \quad$ Displacement in direction $\mathrm{k}$ \\ $\mathrm{u}_{\mathrm{k}, \mathrm{ij}}$ Derivative with respect to $\mathrm{i}$ and $\mathrm{j}$ of $\mathrm{u}_{\mathrm{k}}$ \\ $\theta \quad$ Rotation angle relative to direction 1
}

\section{CONTACT RESOLUTION}

The semi analytical method consists in the summation of elementary solutions known analytically. One of the difficulties is the derivation or the identification of these elementary analytical solutions, such as the well known Boussinesq and Cerruti solutions in isotropic elasticity [1]. The frame is simplified here by supposing the contact between one anisotropic elastic half space and a rigid body. The contact can be controlled by a prescribed load (which is used here) or by a prescribed displacement. Analytical solutions giving the contributions of normal and tangential loading assumed uniform over a single rectangular element will be used. By summation the elastic deflection at each point within and near the contact area will be derived.

The elastic displacements are expressed by a double discrete convolution product between influence coefficients and the pressure or shear at the contact surface. The normal problem and the tangential problem in partial or gross slip are therefore solved.

The resolution is done by minimizing the complementary energy. An algorithm is developed with the conjugated gradient method. To accelerate the calculation, the Fast Fourier Transforms (FFT) are used to perform the double convolution product.

Once the contact problem solved, the strains in the half space are calculated.

\section{ANISOTROPY OF MATERIAL}

Anisotropic materials are defined by the elastic stiffness tensor $\mathrm{C}_{\mathrm{ijk}}$, which satisfies the full symmetry $\mathrm{C}_{\mathrm{ijk}}=\mathrm{C}_{\mathrm{jikl}}=\mathrm{C}_{\mathrm{klij}}$. These materials can be divided into three parts: cubic, orthotropic and anisotropic. Depending on these families of materials, three, nine or twenty one parameters are necessary for defining completely the elastic tensor. Note that in this work the main directions or axes of symmetry are not necessarily the same than the contact ones. In such a situation a reference base 
change has to be done. The elastic stiffness tensor links stresses to strains with this following relation $\sigma_{\mathrm{ij}}=\mathrm{C}_{\mathrm{ijk} l} \cdot \varepsilon_{\mathrm{kl}}$.

\section{INFLUENCE COEFFICIENTS}

The influence coefficients, which link the effort to the displacements or to the strains, for an anisotropic material, are obtained with the Green's functions [2] [3]. These functions can be described explicitly in the Fourier domain, whereas it is more complicated to obtain their formulation in the physical domain due to the general anisotropy of the material [4]. The Fourier domain is therefore used.

A concentrated force (normal or tangential) is applied on the surface of an anisotropic elastic half space. In the absence of body forces, the equations of equilibrium in terms of displacements $\mathrm{u}_{\mathrm{k}}$ are written as

$$
\mathrm{C}_{\mathrm{ijk} \mathrm{l}} \cdot \mathrm{u}_{\mathrm{k}, \mathrm{lj}}=0
$$

Three matrices $3 \times 3$ are defined with the tensor $C_{i j k l}$ and the vectors $\mathrm{n}$ and $\mathrm{m}$, which form a right handed triad with the position vector $\mathrm{x}$. Q, R and T are a double projection of the elastic stiffness tensor.

$$
Q_{i k}=C_{i j k l} \cdot n_{j} \cdot n_{l}, R_{i k}=C_{i j k l} \cdot n_{j} \cdot m_{l}, T_{i k}=C_{i j k l} \cdot m_{j} \cdot m_{l}
$$

Six distinct eigenvalues $\mathrm{p}$ are obtained by calculating the roots of

$$
\operatorname{det}\left(\mathrm{Q}+\mathrm{p} .\left(\mathrm{R}+\mathrm{R}^{\mathrm{T}}\right)+\mathrm{p}^{2} . \mathrm{T}\right)=0
$$

The roots are three pairs of complex conjugates. The complex eigenvectors a of eq. (4) are not a trivial solution. The eigenvectors $\mathrm{b}$ are derived by eq. (5)

$$
\begin{gathered}
{\left[\mathrm{Q}+\mathrm{p} \cdot\left(\mathrm{R}+\mathrm{R}^{\mathrm{T}}\right)+\mathrm{p}^{2} \cdot \mathrm{T}\right] \cdot \mathrm{a}=0} \\
\mathrm{~b}=\left(\mathrm{R}^{\mathrm{T}}+\mathrm{p} \cdot \mathrm{T}\right) \cdot \mathrm{a}
\end{gathered}
$$

The vectors $a$ and $b$ are the Stroh eigenvectors and $p$ the associated Stroh eigenvalues [5]. The Green's functions are then obtained by superposing the six eigensolutions. The calculated displacements and stresses are real. The determination of the roots' sextic equation from which the complex eigenvectors are derived is made numerically.

\section{APPLICATION}

The contact between an elastic anisotropic half space and a rigid indenter, with a spherical tip, is studied. The depth corresponds to direction 3, which means that the surface is defined by directions 1 and 2 . In this example the material properties look like an isotropic material except one of them $\left(\mathrm{E}_{1}\right.$ or $\left.\mathrm{E}_{3}\right)$.

The influence of $E_{1}$ and $E_{3}$ on the contact pressure distribution is shown in Figs. 1 and 2. It is observed that the Young modulus in a direction parallel to the surface $\left(\mathrm{E}_{1}\right.$ here $)$ has a negligible effect (the maximum contact pressure is reduced by $2 \%$ only when $\mathrm{E}_{1}$ is multiplied by a factor 2.5 ), whereas the parameter $\mathrm{E}_{3}$ has a strong influence on the pressure distribution and the contact radius: increase of $69 \%$ of the maximum contact pressure and decrease of the contact radius by $27 \%$ when the Young modulus is increased by a factor 2.5 ) [6] [7].

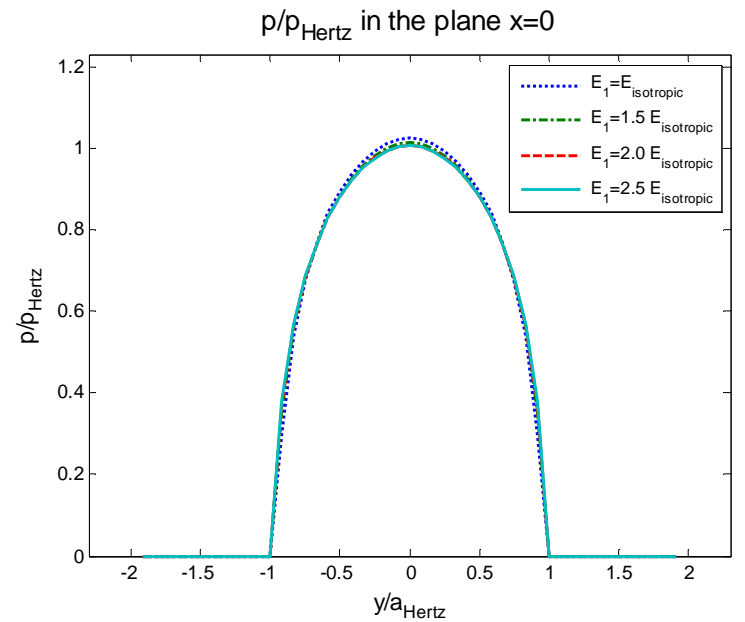

Figure 1: Influence of $E_{1}$ on the contact pressure

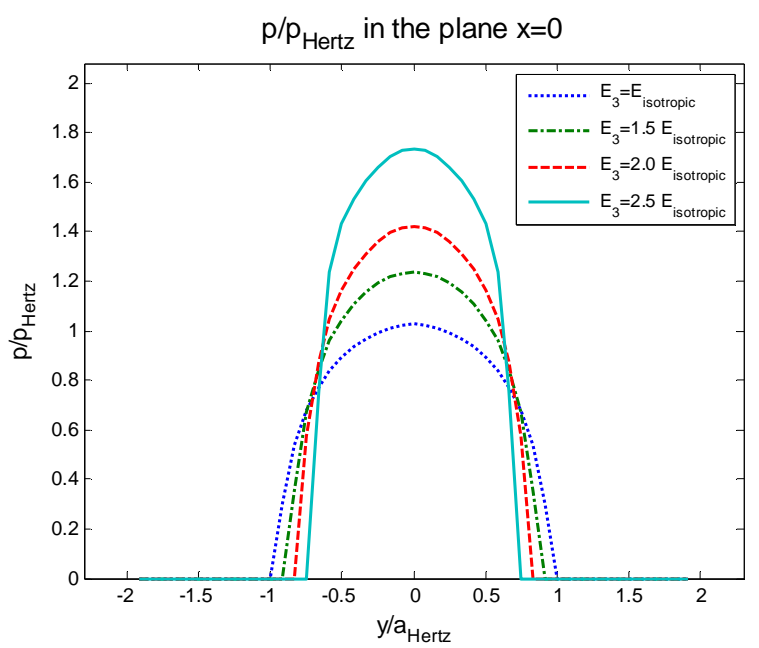

Figure 2: Influence of $\mathbf{E}_{3}$ on the contact pressure

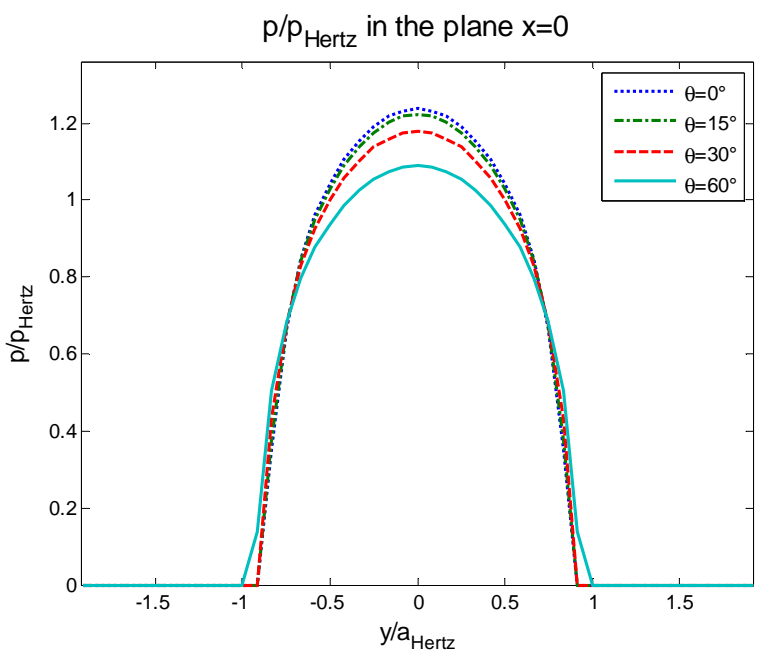

Figure 3: Influence of the material's orientation on the contact pressure 
The effect of the material's orientation relative to the contact is showed in Fig. 3. The material has the properties of an isotropic material except $\mathrm{E}_{3}=1.5 \mathrm{E}_{\text {isotropic, but the material }}$ main direction is different than the contact normal. When the orientation angle $\theta$ around the 1-axis increases up to 90 degrees, the numerical solution converges progressively to the solution where $\mathrm{E}_{3}=\mathrm{E}_{\text {isotropic }}$ and $\mathrm{E}_{2}=1.5 \mathrm{E}_{\text {isotropic }}$ (as shown in Fig. $1)$.

Although the influence of a change of the Young modulus in a direction parallel to the surface (for example $\mathrm{E}_{1}$ ) has a negligible effect on the pressure distribution and contact area, the effect on the stress field is not insignificant. The stress components $\sigma_{11}$ and $\sigma_{33}$ are plotted in Figs. 4 and 5. It can be observed that at the central surface point $\left(\mathrm{x}_{3}=0\right), \sigma_{11}$ is increased by $80 \%, \sigma_{22}$ by $31 \%$, and $\sigma_{33}$ by $94 \%$ when $E_{1}$ reaches 2.5 times $\mathrm{E}_{\text {isotropic }}$.

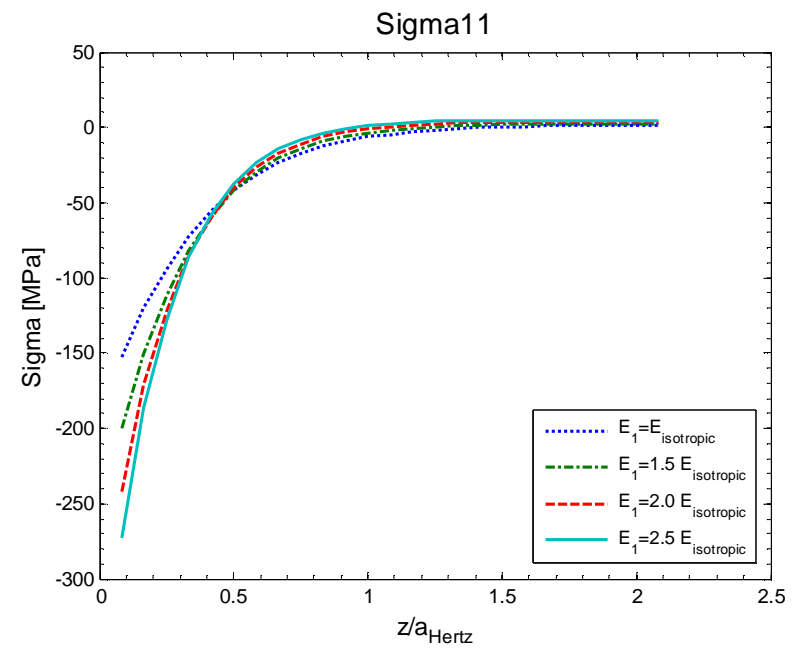

Figure 4: Influence of $E_{1}$ on $\sigma_{11}$

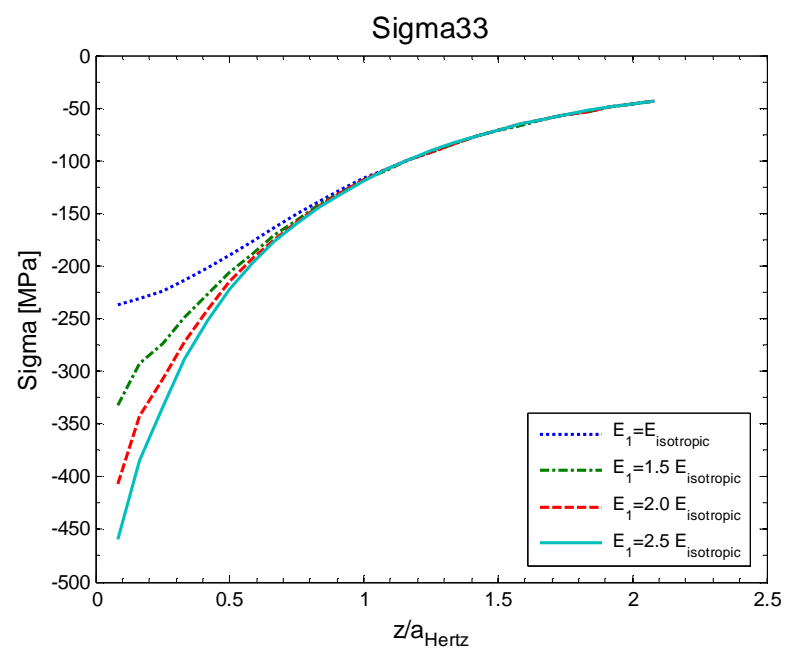

Figure 5: Influence of $E_{1}$ on $\sigma_{33}$

\section{CONCLUSION}

A semi analytic method has been developed for the contact problem of anisotropic elastic materials. The model has been validated by comparison with the solution for isotropic materials. The advantage of this method is the low computing time compared to the finite element method.

It is found that the stiffness along the normal to the contact has a strong influence on the contact solution in terms of pressure distribution and contact; an increase of $E_{3}$ leads to a higher maximum contact pressure and a smaller contact radius. Conversely a change of the Young modulus along a direction parallel to the surface (plane $(1,2)$ ) does not significantly affect the contact pressure distribution (and contact area). It should be however noted that a change in $E_{1}$ or $E_{2}$ does have an effect on the subsurface stress field.

The performance of the method is highlighted by analyzing the effect of the orientation of the material main directions compared to the surface normal.

\section{REFERENCES}

[1] Johnson, K.L., 1985, "Contact mechanics," Cambridge university press, London.

[2] Ting, T.C.T., 1996, "Anisotropic elasticity: theory and applications," Oxford university press, Oxford.

[3] Ting, T.C.T., and Ven-Gen Lee, 1997, "The treedimensional elastostatic Green's function for general anisotropic linear elastic solids," Mech. appl. Math., 50, pp. 407-426.

[4] Pan, E., and Yuan, F.G., 2000, "Three-dimensional Green's functions in anisotropic bimaterials," International Journal of Solids and Structures, 37, pp. 5329-5351.

[5] Ting, T.C.T., 1997, "New explicit expression of BarnettLothe tensors for anisotropic linear elastic materials," Journal of Elasticity, 47, pp. 23-50.

[6] Rodríguez-Tembleque, L., Buroni, F.C., Abascal, R., and Sáez, A., 2010, "3D frictional contact of anisotropic solids using BEM," European Journal of Mechanics A/Solids, 30, pp. 95-104.

[7] He, L., and Ovaert, T.C., 2008, "Three-dimensional rough surface contact model for anisotropic materials," Journal of Tribology, 130. 